\title{
PENGOPERASIAN RFID SEBAGAI OPERATING USER PARKING AREA DENGAN METODE ELEKTRONIK PARKING PRICING (EPP) BERBASIS ARDUINO UNO
}

\author{
Ari Wijayanto, Priyo Sasmoko \\ Program Studi Diploma III Teknik Elektro \\ Fakultas Teknik Universitas Diponegoro \\ Email : ariwijayanto94@gmail.com
}

\begin{abstract}
Ari Wijayanto, Priyo Sasmoko, in this paper explain that for operation RFID Parking Area User Operating Method Electronic Parking Pricing (EPP ) Based Arduino Uno we created to see the problems that occur at this time, where the application of the parking area where the management is still done manually, especially in terms of payments.. We design a tool capable overcome these weaknesses, ranging from providing information about the availability of parking space to the user before entering the parking area to the effectiveness of the method of payment, which uses an identity card balance. With this tool is expected to reduce queuing/ speed up queues of vehicles wanting to enter / exit the parking lot. The system is also supported by the Arduino Uno as the brain to process data from RFID. RTC components to calculate the time and date, LCD display, and a servo motor as the driving door portal. Infrared to close the portal and counting vehicles entering and exiting.
\end{abstract}

Keywords : RFID, Operating User Parking Area, EPP, Arduino Uno

\section{PENDAHULUAN}

Perkembangan dunia teknologi yang sedemikian pesat mendorong manusia untuk menciptakan suatu alat yang serba otomatis sehingga membantu, memudahkan dan mempercepat manusia dalam menyelesaikan pekerjaan. Tempat parkir merupakan awal mula kegiatan dimulai. Faktor kenyamanan dan efektifitas merupakan hal yang penting terutama bagi setiap pengunjung suatu tempat, khususnya di suatu mall atau pusat perbelanjaan. Berdasarkan masalah diatas, kami membuat inovasi berupa miniatur parkir otomatis yang berbayar elektronik, dimana pengoperasian tempat parkir ini menggunakan sebuah kartu identitas/member, dimana hanya yang memiliki kartu tersebut yang bisa mengakses tempat parkir ini dan kartu identitas/member itu mempunyai saldo, yang secara otomatis saldo tersebut akan berkurang sesuai lama waktu parkir kendaran. Jadi pengguna jasa parkir tidak perlu harus menyiapkan uang pas terlebih dahulu atau menunggu kembalian dari operator.

\section{CATU DAYA}

Catu Daya atau power supply adalah suatu rangkaian yang berfungsi sebagai sumber daya untuk mengoperasikan rangkaian yang lain. Jenis rangkaian catu daya cukup banyak tetapi untuk rangkaian yang sederhana biasanya terdiri dari transformator, penyearah, filter, dan regulator. Prinsip dasar untuk memperoleh tegangan searah dapat dijelaskan dalam diagram blok seperti pada gambar 1.

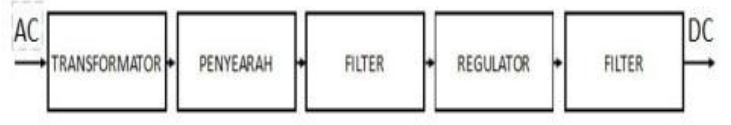

Gambar 1. Diagram Blok Catu Daya
Tegangan AC 220 Volt diturunkan tegangannya menggunakan trafo step down. Setelah itu tegangan disearahkan menggunakan penyearah tegangan atau dioda. Tegangan yang telah disearahkan tadi disaring melalui filter/kapasitor untuk meratakan ripple yang terjadi pada arus agar halus. Tegangan yang halus lalu diregulasi oleh regulator untuk menyesuaikan tegangan yang akan dituju / beban yang dituju, kemudian masuk ke filter lagi agar semakin halus.

\section{ARDUINO}

Arduino secara fisik adalah mikrokontroler. Arduino adalah perangkat keras berbentuk rangkaian elektronik dengan ukuran yang kecil dengan berfungsi sebagai kontroler. Didesain untuk dihubungkan dengan sensor yang akan memberikan informasi keadaan objek atau lingkungan di sekitarnya dan kemudian mengolah informasi tersebut untuk kemudian menghasilkan suatu aksi. Proses ini akan dilakukan berulang-ulang. Siklusnya adalah masukan (input) $\rightarrow$ proses $\rightarrow$ keluaran (output). Terus menerus siklus ini akan diulang. Jadi Arduino adalah sebuah komputer kecil yang mempunyai 'mata' dan 'telinga' untuk mencerna keadaan disekelilingnya dan kemudian beraksi sesuai 'nalar' yang telah kita tanamkan di dalam 'otak'-nya.

Arduino adalah pengendali mikro singleboard yang bersifat open-source, diturunkan dari Wiring platform, dirancang untuk memudahkan penggunaan elektronik dalam berbagai bidang. Hardware-nya memiliki prosesor Atmel AVR dan softwarenya memiliki bahasa pemrograman sendiri. Sebuah chip mikrokontroler dengan jenis AVR dari perusahaan Atmel inilah yang merupakan komponen utama dari arduino. Gambar 2 merupakan tampilan papan Arduino. 


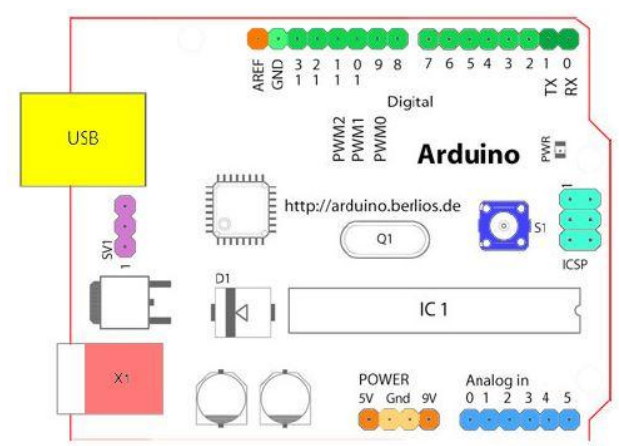

Gambar 2. Bagian Bagian Papan Arduino

\section{RFID (RADIO FREQUENCY IDENTIFICATION)}

Identifikasi suatu objek sangat erat hubungannya dengan pengambilan data. Salah satu metoda identifikasi yang dianggap paling menguntungkan adalah auto-ID atau Automatic Identification, yaitu metoda pengambilan data dengan identifikasi objek secara otomatis tanpa ada keterlibatan manusia. Auto-ID bekerja secara otomatis sehingga dapat meningkatkan efisiensi dan mengurangi kesalahan dalam memasukan data. RFID adalah salah satu dari berbagai teknologi yang dikelompokkan dalam Automatic Identification (Auto ID), seperti barcode, smart cards, voice recognition, serta identifikasi biometric seperti retinal scan, dan Optical Character Recognition (OCR). Teknologi RFID adalah sarana untuk mengumpulkan data tentang barang tertentu tanpa perlu sentuhan langsung atau melihat pembawa data, yaitu melalui penggunaan inductive coupling atau gelombang elektromagnetik. Sebagai pembawa data adalah microchip yang melekat pada antena (bersama- sama disebut reader atau tag), dan antena tersebut memungkinkan chip untuk mengirimkan informasi ke reader (transceiver) dalam kisaran yang diberikan dan dapat meneruskan informasi ke sebuah host komputer. Middleware (perangkat lunak untuk membaca dan menulis tag) dan tag dapat ditingkatkan dengan enkripsi data untuk aplikasi keamanan tingkat tinggi. Anti tabrakan algoritma juga dapat diimplementasikan untuk tag jika beberapa tag digunakan untuk dibaca secara bersamaan. Teknologi RFID mudah digunakan dan sangat cocok untuk operasi otomatis. RFID mengkombinasikan keunggulan yang tidak tersedia pada teknologi identifikasi yang lain. RFID dapat disediakan dalam perangkat yang hanya dapat dibaca saja (Read Only) atau dapat dibaca dan ditulis (Read/Write), tidak memerlukan kontak langsung maupun jalur cahaya untuk dapat beroperasi, dapat berfungsi pada berbagai variasi kondisi lingkungan, dan menyediakan tingkat integritas data yang tinggi. Pada sistem RFID umumnya, tag atau reader ditempelkan pada suatu objek. Setiap tag dapat membawa informasi yang unik seperti serial number, model, warna, tempat perakitan, dan data lain dari objek tersebut. Ketika tag ini melalui medan yang dihasilkan oleh reader RFID/RFID reader yang kompatibel, tag tersebut akan mentransmisikan informasi yang ada di dalamnya kepada RFID reader, sehingga proses identifikasi objek dapat dilakukan.

\section{KEYPAD MATRIX 4 X 4}

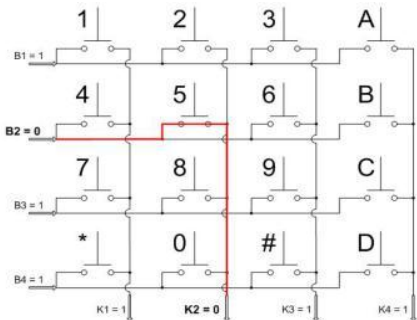

Gambar 3. Susunan tombol dan jalur pada keypad

Pada gambar 3 diperlihatkan susunan tombol keypad. Keypad digunakan sebagai suatu input antarmuka pada mikrokontroler. Keypad sesungguhnya terdiri dari sejumlah tombol tekan, yang terhubung sebagai baris dan kolom dengan susunan seperti yang ditunjukkan pada gambar 2.18 Agar mikrokontroler dapat melakukan reader dari keypad, maka port mengeluarkan salah satu bit dari 4 bit yang terhubung pada kolom dengan logika low " 0 " dan selanjutnya membaca 4 bit pada baris untuk menguji jika ada tombol yang ditekan pada kolom tersebut.

\section{LCD (LIQUID CRYSTAL DISPLAY)}

Sensor LCD Character atau Karakter, adalah LCD yang tampilannya terbatas pada tampilan karakter, khususnya karakter ASCII (seperti karakter-karakter yang tercetak pada keyboard komputer).

Sedangkan LCD Graphics atau Grafik, adalah LCD yang tampilannya tidak terbatas, bahkan dapat menampilkan foto. LCD Grafik inilah yang terus berkembang seperti layar LCD yang biasa dilihat di notebook / laptop. Dalam pembahasan kali ini akan dikonsentrasikan pada LCD Karakter. Alamat pin LCD ditunjukkan pada gambar 4.

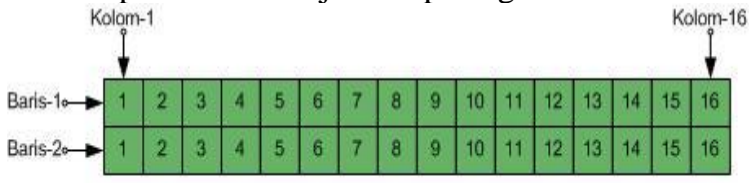

Gambar 4. Alamat Pin LCD

\section{REAL TIME CLOCK (RTC)}

DS1307 merupakan Real-time clock (RTC) dengan jalur data parallel yang memiliki Antarmuka serial Two-wire (I2C), Sinyal luaran gelombangkotak terprogram (Programmable squarewave), Deteksi otomatis kegagalan-daya (power-fail) dan rangkaian switch, Konsumsi daya kurang dari 500nA menggunakn mode baterei cadangan dengan operasional osilator. Tersedia fitur industri dengan ketahana suhu: $-40^{\circ} \mathrm{C}$ hingga $+85^{\circ} \mathrm{C}$. Tersedia dalam 
kemasa 8-pin DIP atau SOIC. Gambar 5 merupakan rangkaian RTC DS1307

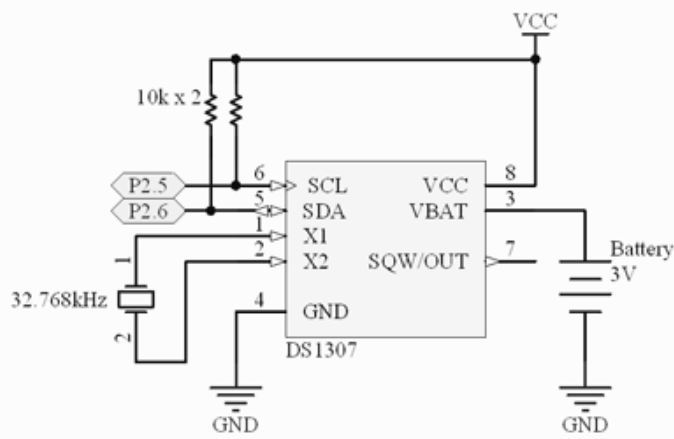

Gambar 5. Rangkaian RTC DS1307

\section{CARA KERJA ALAT \\ Blok Diagram Sistem}

Cara kerja pengoperasian RFID sebagai operating user parking area dengan metode elektronik parking pricing (EPP) berbasis Arduino uno ini terdiri dari beberapa blok komponen, yang selanjutnya melakukan proses yang dapat dilihat secara umum pada blok diagram yang ditunjukan oleh gambar 6.

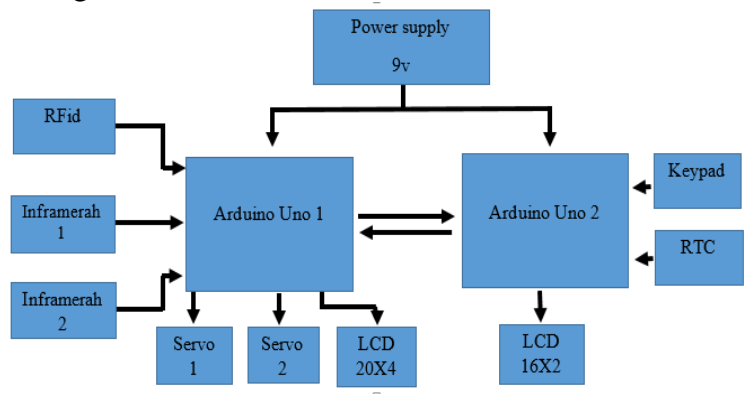

Gambar 6.. Blog Diagram Sistem

\section{Rangkaian Keseluruhan}

Gambar 7 memerlihatkan rangkaian keseluruhan dari alat yang akan dibuat. Dengan tugas masing masing dimana 2 buah Arduino tersebut saling di hubungkan dengan koneksi secara serial,lalu tag card RFID yang telah diregistrasi ketika di dekatkan pada RFID maka akan mengirim data pada Arduino 1 kemudian diteruskan pada Arduino 2 sebagai database apakah tag RFID tersebut compatible, lalu RTC mulai menghitung waktu registrasi tersebut dan mengembalikan data pada Arduino 1 untuk menampilkan database pada LCD dan menggerakan motor untuk membuka palang, kemudian ketika body mobil telah melewati infra merah, arduino 1 akan kembali menggerakan motor untuk menutup palang, lalu perhitungan waktu parkir pun dimulai. Begitu juga ketika mobil keluar, maka ketika tag card RFID di dekatkan pada RFID arduino 2 akan mengkalkulasi waktu dan biaya dengan menggunakan RTC sesuai program, lalu dilanjutkan ke arduino 1 untuk membuka palang, kemudian ketika body mobil telah melewati infra merah, Arduino 1 akan kembali menggerakan motor untuk menutup palang.

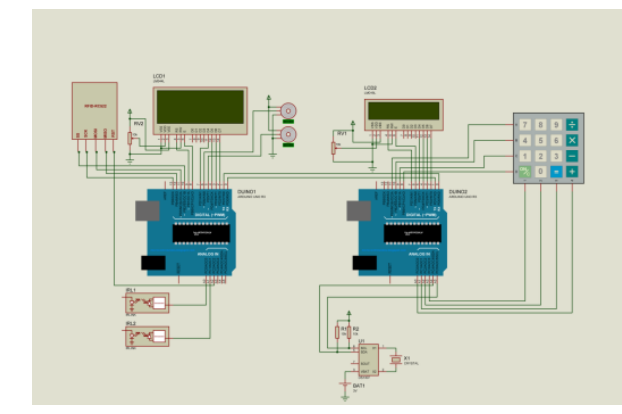

Gambar 7. Rangkaian Keseluruhan Sistem

\section{PENGUKURAN DAN PENGOPERASIAN Rangkaian Catu Daya}

Pengukuran rangkaian catu daya pada dasarnya bertujuan untuk mengetahui tegangan keluaran dari rangkaian catu daya agar tegangan keluaran dapat stabil sebagai catu daya pada masingmasing modul. Pada sistem ini menggunakan rangkaian catu daya dengan tegangan output sebesar 5V. Titik pengukuran yang dilakukan meliputi input trafo yaitu dari tegangan jala-jala PLN, output dari trafo yaitu tegangan PLN yang telah diturunkan oleh trafo step down, keluaran dioda sebagai keluaran setelah tegangan disearahkan, input dan output regulator, serta tegangan keluaran akhir.

Adapun langkah-langkah yang dilakukan untuk mengukur sistem minimum AVR ATmega16 adalah sebagai berikut:

- Menghubungkan catu daya dengan jala-jala PLN.

- Mengukur tegangan tiap-tiap bagian yang telah ditentukan sebelumnya.

- Mencatat hasil pengukuran

Titik pengukuran catu daya diperlihatkan pada gambar 8 .

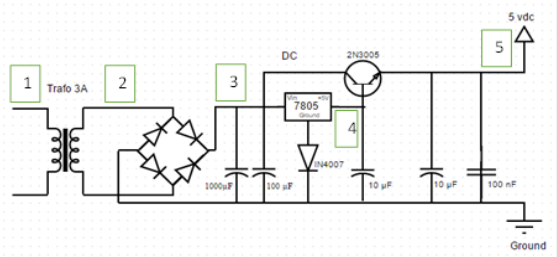

Gambar 8. Pengukuran Rangkaian Catu Daya

Tabel 1. Hasil Pengukuran Catu Daya

\begin{tabular}{clc}
\hline No. & Bagian Yang Diukur & Tegangan \\
\hline 1 & $\begin{array}{l}\text { Tegangan Input Trafo } \\
\text { Tegangan Output Trafo }\end{array}$ & $220 \mathrm{~V}_{\mathrm{AC}}$ \\
2 & $\begin{array}{l}\text { (a) } \\
3\end{array}$ & $\begin{array}{l}\text { Tegangan Output Dioda } \\
\text { Tegangan Output LM }\end{array}$ \\
$\begin{array}{l}\text { 7805+ Dioda } \\
4\end{array}$ & $5,7 \mathrm{~V}_{\mathrm{DC}}$ \\
$\mathbf{5}$ & Tegangan output LM7805 & $5 \mathrm{Vdc}$ \\
6 & Tegangan Output 2n3055 & $5 \mathrm{~V}_{\mathrm{DC}}$ \\
\hline
\end{tabular}




\section{Rangkaian Modul RFID}

Pada proses pengukuran rangkaian modul RFID terdapat beberapa langkah yang harus dilakukan, yaitu sebagai berikut :

- Menghubungkan masukan rangkaian modul RFID dengan catu daya $5 \mathrm{~V}$.

- Mengukur tegangan pada saat modul RFID tidak didekati tag.

- Mengukur tegangan pada saat modul RFID didekati tag.

- Mencatat semua hasil pengukurannya.

Gambar 9. berikut menunjukkan pengukuran tegangan pada rangkaian modul RFID.

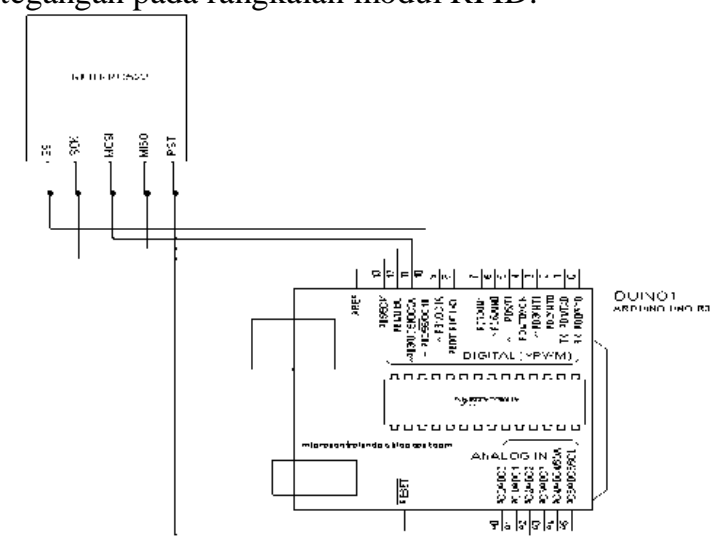

Gambar 9. Pengukuran Rangkaian Modul RFID

Tabel 2. Hasil Pengukuran Rangkaian Modul RFID

\begin{tabular}{|c|c|c|c|}
\hline \multirow[b]{2}{*}{ No. } & \multirow{2}{*}{$\begin{array}{c}\text { Bagian Yang } \\
\text { Diukur }\end{array}$} & \multicolumn{2}{|c|}{ Tegangan } \\
\hline & & $\begin{array}{c}\text { Tanpa } \\
\text { Tag }\end{array}$ & $\begin{array}{l}\text { Ada } \\
\text { Tag }\end{array}$ \\
\hline 1 & Tegangan VCC & 3,8 & \\
\hline & Tegangan input pin & 3,8 & \\
\hline 2 & RFID & & \\
\hline 3 & $\begin{array}{l}\text { Tegangan output } \\
\text { RFID }\end{array}$ & 0 & 2,4 \\
\hline
\end{tabular}

\section{Rangkaian LCD Display 2x16}

Titik pengukuran rangkaian LCD display 2x16 diperlihatkan pada gambar 10 .

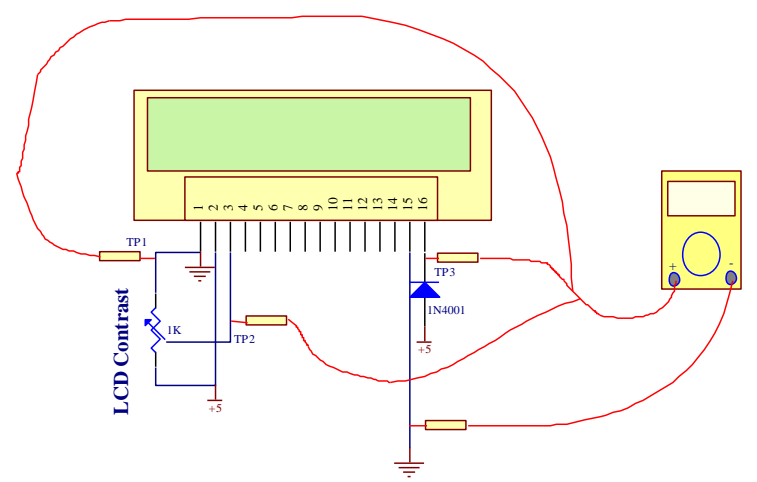

Gambar 10. Pengukuran LCD Display 2x16
Tabel 3. Hasil Pengukuran Tegangan Catu LCD (TP 1)

\begin{tabular}{ccc}
\hline $\begin{array}{c}\text { Tegangan } \\
\text { terukur }\end{array}$ & $\begin{array}{c}\text { Tegangan } \\
\text { Semestinya }\end{array}$ & Error \\
\hline$+4,85 \mathrm{~V}$ & $+5 \mathrm{~V}$ & $3 \%$ \\
\hline
\end{tabular}

\section{Pengujian Sistem}

Dalam pengambilan data pengujian alat pengoperasian RFID sebagai operating user parking area dengan metode elektronik parking pricing (EPP) berbasis Arduino uno dapat diperoleh datadata hasil pengukuran di atas, selain itu dari pengujian sistem juga diperoleh data mengenai sistem dalam bekerja. Maka dari itu penulis menguji kerja alat dengan beberapa sampel. Hasil pengukuran disajikan dalam tabel 4dan 5.

Tabel 4. Jarak Baca RFID Terhadap Tag

\begin{tabular}{|c|c|c|}
\hline Jarak Baca & Keterangan & Kondisi \\
\hline & & Palang \\
\hline $1 \mathrm{~cm}$ & Terbaca & $\begin{array}{c}\text { Membuka } \\
\text { Palang }\end{array}$ \\
\hline $1,5 \mathrm{~cm}$ & Terbaca & $\begin{array}{l}\text { Membuka } \\
\text { Palang }\end{array}$ \\
\hline $2 \mathrm{~cm}$ & Terbaca & $\begin{array}{l}\text { Membuka } \\
\text { Palang }\end{array}$ \\
\hline $2,5 \mathrm{~cm}$ & Terbaca & $\begin{array}{l}\text { Membuka } \\
\text { Palang }\end{array}$ \\
\hline $3 \mathrm{~cm}$ & Terbaca & Membuka \\
\hline $3,5 \mathrm{~cm}$ & Tidak Terbaca & Palang Tertutup \\
\hline $4 \mathrm{~cm}$ & Tidak Terbaca & Palang Tertutup \\
\hline
\end{tabular}

Tabel 5. Pengujian Tag RFID

\begin{tabular}{ccc}
\hline $\begin{array}{c}\text { Nomor } \\
\text { Kartu }\end{array}$ & Kondisi & Status \\
\hline A1E0F255 & Terdaftar & Cocok \\
F33BF455 & Terdaftar & Cocok \\
55DDF255 & Terdaftar & Cocok \\
45B3F255 & Belum Terdaftar & Tidak \\
& & Cocok \\
36E6F255 & Belum Terdaftar & Tidak \\
& & Cocok \\
\hline
\end{tabular}

\section{Kesimpulan}

Dalam penelitian ini, kesimpulan yang dapat diambil dari teori penunjang yang telah ringkas dalam bab-bab terdahulu maupun pengalaman yang didapat selama proses perancangan alat, yaitu:

- RFID dapat difungsikan sebagai indentitas pelanggan yang baik karena tag RFID yang belum terdaftar tidak dapat digunakan untuk mengakses parkir.

- RFID reader dapat membaca tag RFID dalam jarak $3 \mathrm{~cm}$ sedangkan dalam datasheet $5 \mathrm{~cm}$

- RTC DS1307 dengan backup baterai dapat digunakan sebagai penghitung waktu yang baik sehingga perhitungan biaya tetap sesuai karena berdasarkan pengujian walau tidak ter supply 
tegangan sumber RTC tetap berjalan sebagaimana mestinya.

\section{DAFTAR PUSTAKA}

1. Malvino. 1995. Prinsip-prinsip Elektronkasi. Jakarta : Erlangga.

2. Van Vlack. Lawrench, Ilmu dan Teknologi Bahan, Erlangga, hal 186

3. Djuaji, Very. 2011, Pengenalan Arduino. hal.9

4. Finkenzeller Klaus, 2010, RFID Handbook, 319

5. Elektuur, B.V. 1986. 301 Rangkaian. Diterjemahkan oleh: Ignatius. Jakarta: Elex Media Komputindo.

6. Tri, 2014 Metode Penulisan Karya Ilmiah, Bandung: Kelompok keahlian Ilmu Kemanusian Institut Teknologi Bandung.

7. Jogiyanto, 2003, Konsep dasar Pemrograman Bahasa C, Yogyakarta: Andi.

8. Annonimous. 2012. Mengenal Arduino UNO. Diunduh dari http://www.sahabatinformasi.com/2012/07/mengenal-arduinouno.html pada 25 mei pukul 20.02 WIB. 